\title{
Medical students' knowledge, attitude, and practice of complementary and alternative medicine: a pre- and post-exposure survey in Majmaah University, Saudi Arabia
}

Mohammed Abdullah Al

Mansour'

Abdullah MN Al-Bedah²

Mohammed Othman

AIRukban $^{3}$

Ibrahim S Elsubai

Elsadiq Yousif Mohamed ${ }^{4}$

Ahmed Tawfik El Olemy ${ }^{2}$

Asim AH Khalil ${ }^{2}$

Mohamed KM Khalil ${ }^{2}$

Meshari Saleh Alqaed ${ }^{2}$

Abdullah Almudaiheem ${ }^{2}$

Waqas Sami Mahmoud ${ }^{4}$

Khalid Altohami Medani ${ }^{4}$

Naseem Akhtar Qureshi ${ }^{2}$

'College of Medicine, Majmaah University, Al Majma'ah, ${ }^{2}$ National

Center of Complementary and

Alternative Medicine, Ministry of

Health, ${ }^{3}$ Department of Family

Medicine and Community Medicine,

College of Medicine, King Saud

University, Riyadh, ${ }^{4}$ Department of Community Medicine and Public

Health, College of Medicine, Majmaah

University, Al Majma'ah, Saudi Arabia

Correspondence: Naseem Akhtar Qureshi National Center for Complementary and Alternative Medicine, PO box 88300 , Riyadh II 662, Saudi Arabia

Tel +966 I I450 0147

Fax +966 I | 4709602

Email qureshinaseem@live.com
This article was published in the following Dove Press journal:

Advances in Medical Education and Practice

3 June 2015

Number of times this article has been viewed

Background: Evidently, complementary and alternative medicine (CAM) is a recognized medical practice that efficiently uses multiple treatment therapies and techniques in the prevention and management of a variety of human disorders. Many medical schools have integrated CAM curriculum in medical education system worldwide. Research in knowledge, attitude, and practice (KAP) of diverse health professionals exposed to CAM courses is important from many perspectives including improvement in KAP and teaching skills of faculty, together with capacity building and curriculum development.

Objective and setting: This pre- and post-design cross-sectional study aimed to assess CAM-KAP of two intakes of medical students in Majmaah University, Saudi Arabia.

Methods: The second-year medical students of the first (year 2012-2013) and second (year 2013-2014) intake ( $\mathrm{n}=26$ and 39, respectively) were selected for this study. A reliable, 16-item self-administered questionnaire was distributed among all the students for answering before and after the 48-hour CAM course. The data were analyzed using appropriate statistical test of significance.

Results: Medical students' knowledge and attitude toward CAM significantly improved across some subitems of CAM questionnaire with a positive trend in the rest of its items including their views on CAM practices.

Conclusion: CAM course tends to have a positive impact on KAP of medical students. The preliminary results of this study call for further research with a larger sample in academic settings across the nation.

Keywords: traditional medical system, medical schools, undergraduate medical students, curriculum, Saudi Arabia

\section{Introduction}

Non-allopathic medical systems have diverse intervention approaches directed toward balancing mind-body-spirit dimension of a whole person with or without disease. ${ }^{1,2}$ The holistic concept is an ideal principle underlying traditional medical systems/ integrative medicine (IM), which include ayurveda, naturopathy and yoga, unani medicine and homeopathy, traditional Chinese and Japanese medicine, and prophetic medicine..$^{3-5}$ Traditional treatments were used effectively in innumerable diseases since ancient times and continued to survive and flourish, although research in holistic system approaches remained poorly organized. ${ }^{6}$ However, over the past few decades, research including randomized clinical trials, systematic reviews, meta-analyses, 
and observational studies into complementary and alternative medicine (CAM) is beginning to reveal empirically the underlying mechanisms of actions and effectiveness of traditional treatment modalities in various diseases, ${ }^{7-11}$ which accordingly are cost-effective and efficient with minor adverse effects comparable to placebo. ${ }^{12,13}$ In US, in the year 2007 , adults (age over 18) spent $\$ 33.9$ billion out-of-pocket on visits to CAM practitioners and purchases of CAM products, classes, and materials. ${ }^{14}$ In another report, Davis and Weeks estimated that over 30 million adults reported out-of-pocket expenditures on CAM services, and of these individuals, 7.2 million were heavy CAM spenders with a mean annual expenditure of $\$ 1,385$, thus suggesting that out-of-pocket spending on CAM is concentrated. ${ }^{15}$ A large number of surveys conducted worldwide also evidenced the emerging popularity of CAM use, either adjunctive or alternative, in acute and chronic human diseases, attributable to a variety of plausible reasons including patients' dissatisfaction with severe adverse effects and high costs of allopathic medications. ${ }^{16,17}$ Approximately $40 \%$ of adults and approximately $11.8 \%$ of children had used CAM therapies in the past 12 months in US. ${ }^{16}$ Furthermore, World Health Organization estimated that approximately $75 \%$ of the world's health care is technically alternative. ${ }^{13}$ The use of CAM is reported to be more common in poor population and underserved communities of the world. ${ }^{18}$

In the eastern world, the bedrock of traditional medicine, many traditional medical schools and national centers of CAM were established long time back to meet the increasing demand of health consumers and health providers, to regulate CAM practices with a focus on research and training, and similar developmental trends driven by policy statements of influential bodies ${ }^{19,20}$ have been rapidly emerging in the western world. ${ }^{21}$ Notably, despite several observed challenges and barriers including curriculum being already too full, the resistance by faculty, relative lack of evidence-based CAM contents, unavailability of reliable resources, and development of teaching and assessment tools, ${ }^{22,23} \mathrm{CAM}$ curriculum is increasingly incorporated in many universities of the world to teach medical students about CAM practices, as an elective or mandatory course. ${ }^{24,25}$ How medical students and professionals perceive CAM and also how they develop their related knowledge base and practice is relatively an old avenue for research in eastern world, although western world has produced huge data on this particular perspective over a few decades. ${ }^{26}$

\section{Local landscape of CAM}

Notably, there is scant literature on knowledge, attitude, and practice (KAP) of CAM among medical students, professionals, and public in eastern Mediterranean region countries. A PubMed search of relevant literature using key word complementary and alternative medicine retrieved a dozen of articles; ${ }^{27-39}$ however, only few studies assessed the KAP of public, professionals, primary care physicians, and pharmacists. ${ }^{27,30-32,36}$ The results of these studies suggest that CAM therapies, especially herb preparations and locally known therapies are used by a substantial number of patients, and public and professionals have positive attitudes toward CAM, identified some barriers against CAM, and have good knowledge in CAM, and further express to have more knowledge in CAM and support its integration into primary health care $27,30-32,36$ and medical schools. ${ }^{39} \mathrm{We}$ found only one study from Kuwait that assessed KAP of CAM therapies among medical and pharmacy students. ${ }^{36}$ Therefore, this team conducted a KAP study among medical undergraduate students of Majmaah University in the KSA.

\section{Rationale}

Over the last 100 years, biomedicine, mainly represented by pharmaceutical industries and phyto-pharmaceuticals, has consistently utilized medications effectively for acute injuries, infectious diseases, and a variety of chronic, noninfectious diseases. ${ }^{17,40}$ However, a proportion of patients, due to multiple biopsychosocial and cultural reasons, do not use conventional medications and prefer traditional therapies, including herbal products. ${ }^{13,16,18,41,42}$ In addition, chronic patients do not respond to conventional medications and develop serious adverse effects and other complications that also drive them to seek other forms of CAM treatments. ${ }^{2,17-19}$ Several surveys have reported the increasing use of traditional therapies by patients and population at large, the latter group use for health promotion, good quality of life, and prevention purposes. ${ }^{13,17,18}$ Like traditional practitioners, conventional doctors began to use frequently traditional therapies in their practice. ${ }^{43}$ Notably, several international health organizations and research institutions supported the use of and research and training on traditional therapies across the world..$^{19,20}$ Furthermore, many medical schools and universities integrated CAM curriculum into their medical education system in the western world..$^{21,24,25}$ This is to impart required theoretical and empirical knowledge in CAM to medical students and prepare them to practice effectively and efficiently IM in 
future. All these driving forces were important determinants for adopting CAM curriculum for teaching medical students in Majmaah University. This study assesses the impact of pre- and post-CAM course on attitudes, knowledge, and experience of two intakes of second-year medical students in Majmaah University. Another important rationale is that this CAM course may be adopted by other universities in KSA and Arabian Gulf countries.

\section{Significance}

Besides improving KAP of CAM therapies among medical students, the students' feedback about this course will help curriculum developers to further align it with students' expressed needs in CAM course. Medical students exposed to CAM course may practice as CAM doctors and also take up advanced studies in IM in future. By extension, they may also disseminate gained CAM information to the community with whom they have frequent discussions at several leisure places in KSA.

\section{Hypothesis}

We hypothesize that the exposure of medical students to CAM course will improve their KAP of CAM.

\section{Materials and methods Setting}

The Majmaah University was established in accordance with a decree of the Custodian of the Two Holy Mosques King Abdullah Bin Abdul Aziz Al-Saud and the Prime Minister and Chairman of Higher Education on Ramadan 3, $1430 \mathrm{H}$ corresponding to August 24, 2009G. The name of Majmaah University is derived from Majmaah Governorate, located $180 \mathrm{~km}$ north of Riyadh city. Majmaah University serves five provinces, which have several cities and villages, and their total population is approximately 250,000 . The University's main campus is located in the south part of Majmaah City. The total area of Majmaah province is $30,000 \mathrm{~km}^{2}$. The Majmaah University is the value-added icon to the people of the region in social, cultural, research, and education pathways. A separate royal decree vide number 194/A and dated ZulHejjah 30, 1430 corresponding to October 17, $2009 \mathrm{G}$ was issued to appoint its rector with higher rank to accelerate the establishment of this University. According to the rector, Majmaah University, a beacon of advanced knowledge and enlightenment, shall offer high-quality education to prospective students in the region. ${ }^{44}$

\section{Study design, sample, and data collection}

This cross-sectional study has pre- and post-design. Medical undergraduates of second year from first intake $(n=26)$ of year 2012-2013 and second intake $(n=39)$ of year 2013-2014 were selected for this study. Two students from first intake and three students from intake 2 joined the course late and could not fill out pretest questionnaire. So they were excluded from this study, and the total number of students in the sample was 65 , whose pre- and posttest responses were available. Prior to filling out the questionnaire, the participating students were informed the following: the team will be conducting a survey of attitudes, awareness, and self-perceived skills in CAM use, and the participants' input will be used to construct future CAM educational programs for students and residents, and allied health professionals. The research team will maintain the participants' anonymity and confidentiality. The survey will never be associated with any information that could identify the participants personally. Only aggregated data of intake 1 and intake 2 from the survey will be reported. As there are no right or wrong answers to any item, the participants must respond to each item according to how they feel about CAM at that point in time. Participation in this study is voluntary. The participants may decide not to complete this survey at any time without penalty. Completion of this survey indicates their consent to participate.

Thereafter, a self-administered questionnaire was given to all participants in a classroom, and they were advised to fill it out before beginning the CAM class. They were guided that if they do not understand any item on the questionnaire, they should feel free to contact one of the team members supervising administration of this questionnaire. All questionnaires were collected and checked carefully for their completeness. If there was any item on the questionnaire unanswered, then that particular student was contacted to complete it before leaving the classroom. Subsequently, the students were taught CAM course longitudinally, and thereafter, they were given the same questionnaire for filling out. They were asked to completely fill out the questionnaire. All questionnaires were collected and checked carefully for their completeness. The specific details of the CAM curriculum and questionnaire are summarized in the following sections.

\section{CAM training course}

The Department of Community Medicine of College of Medicine, Majmaah University in collaboration with National Center of Complementary and Alternative Medicine (NCCAM), Ministry of Health, Riyadh developed 
a comprehensive course on CAM for the academic year 2013-2014. The module title and code of this course are CAM and MEDU 230, respectively. The credit hours for this mandatory course were $2(2+0+0)$ hours, and module duration was 48 hours. Module commencement was in the sixth semester. There were one module coordinator, one associate coordinator, and two module members. Furthermore, 20 module teachers included faculty and NCCAM staff. All teachers have either MD/PhD (17) or MBBS (3) degrees. This module was approved by a number of committees and departments of Majmaah University. This course mainly focused on an overview of CAM and most commonly used CAM modalities worldwide, in addition to CAM therapies in vogue locally. However, all teachers were requested to provide information on their topics and discuss the following competency-based areas, such as basic definitions of CAM and IM, history, epidemiological trends, common clinical indicators and applications, adverse effects and drug-drug interactions, research-based evidence for efficacy, resources for comprehensive CAM information, and training standards for CAM practitioners. ${ }^{45-47}$

This course proposed CAM teaching in terms of mandatory module, core curriculum lectures, and inclusion in problem-based learning at undergraduate and residency level, and later on followed by continuing education modules as well as research and clinical fellowship. The aims of this module are as follows: to improve future doctors' knowledge in CAM practices and their place in health care system, to build their communication skills to guide patients about CAM modalities and its credentials and legal and regulatory issues, to develop search skills and critical appraisal of relevant literature related to CAM, to evaluate evidence for the safety and efficiency of CAM techniques, and to develop deeper understanding regarding its integration into conventional medical system - IM. By the end of the module, students should be able to learn the following: 1) to define $\mathrm{CAM}$ and related names and terminologies and their differences in meanings (A);2) to classify CAM modalities and types (A); 3) to identify common CAM practices patients use in the KSA such as Arabic and Islamic traditional healing practices (A, B, D); 4) to computer search for relevant CAM literature and critical appraisal for finding evidence, efficacy, safety, and adverse effects of CAM modalities (E); 5) to identify CAM therapies to which diseases are most responsive $(\mathrm{B}, \mathrm{C}) ; 6)$ to develop communication skills to discuss CAM practices with patients $(\mathrm{B}, \mathrm{D})$; and 7$)$ to identify the role of NCCAM as a national reference for all CAM-related issues such as practice, regulations, and accreditation (A, B, E). These learning outcomes of five levels were described as follows: A - scientific in their approach to practice, $\mathrm{B}$ - proficient in clinical care, $\mathrm{C}$ - professional, D - community conscious, and E - scholar. This module contains 13 contents/topics, five seminars together with a field visit to CAM clinic in King Khalid Military Hospital in Hafr El-Baten, and an assignment, each of which is described briefly in this module (available upon request from AM AlBedah). All teachers adopted a number of teaching methods; interactive lecturers and assigned students conducted seminar sessions/presentations using developed guidelines. Each student was advised to submit a report within a week about CAM from evidence to integration assignment, which should be based on a critical appraisal of a paper related to CAM discussing its PICO (population, patient, problem, intervention, comparison and outcome) and quality. Similarly, each student was asked to submit a report about his experience and observations during field visit to the King Khalid Military Hospital. Besides, students were provided reading materials including textbooks and CAM journals. The whole idea of teaching CAM course interactively was that students must participate actively in presentation and discussion and help develop guidelines for seminar sessions and should not sit in the class as passive spectators and consequently develop meaningful knowledge, favorable attitude, and usage of CAM therapies and comprehend its connectivity to biomedical model. The duration of lectures and exams were as follows: each interactive lecture ( $n=13$, each of 2 hours), student-led seminar and assignment ( $\mathrm{n}=6$, each of 2 hours), field visit ( $n=1,6$ hours), midterm exam ( $n=1,2$ hours), and final exam $(n=1$, of 2 hours), so the grand total duration of lectures and two examinations was 48 hours.

\section{CAM questionnaire}

We searched relevant international literature for identifying questionnaires used in CAM-KAP research in general but especially pre- and post-surveys related to CAM and IM. ${ }^{3,17,48-50}$ From these researches, we selected an evaluation tool that was used in two surveys. ${ }^{17,50}$ This validated questionnaire is about CAM survey of knowledge and attitudes of health professional students originated from Kreitzer's University of Minnesota Academic Health Center and has been used subsequently in many studies. ${ }^{17,50}$ The questionnaire used in the present study was adapted following suggestions of three CAM experts, two faculty staff, and some second-year medical students. Accordingly in first round, the research team simplified the English wordings of some items and subitems of this questionnaire. 
This modified questionnaire was pretested on 15 medical students before its application. Students provided no suggestions for any significant changes in the questionnaire. Notably, all components of this questionnaire were retained, which include the following: 1) general attitudes toward CAM; 2) barriers to use CAM practices worldwide; 3 ) what primary worldview or framework guides people's personal health views; 4) CAM approaches - "alternative" or mainstream?; 5) effectiveness of CAM modalities; 6) CAM training received by participants; 7) need of further CAM training; 8) personal use of CAM; 9) CAM approaches in participants' practice; 10) sources of information about CAM; 11) evidence for use of CAM practices; 12) views about CAM as a practitioner; 13) a female case of seasonal allergy and choice of CAM therapies; 14) in a case of acute appendicitis, which CAM therapies are most effective; 15) influence of various factors on people's response to several approaches to health care, and 16) people's views about health and healing. Additional questions included were as follows: 1/17) Do you believe that your spiritual or religious beliefs influence your attitudes toward CAM? 2/18) Describe a CAM training you have had. 3/19) Overall comments on CAM practices or education. For items 1, 2, 5, $8,12,15$, and 16, the research team used five-point Likert scale (strongly agree, agree, neutral, disagree, and strongly disagree) for rating participants' responses, and some items - 4, 6, 7, 9, and 11 were rated by using four-point Likert scale. The Likert scale was not used to rate medical students' responses related to items $3,10,13$, and 14 and three added questions of this tool. We used Likert scale because openended questionnaires are filled out completely compared to closed-ended questionnaires. ${ }^{51}$ The sociodemographic data included only age of participants, and no female student was enrolled in Majmaah University at the time of this study. We have used only these items - 1-3, 10, 12, 15-19- of this questionnaire in this study as the emitted items do not address specifically individual CAM approach (a second paper addressing the rest of items is forthcoming soon).

\section{Data analysis}

The recorded responses on pre- and post-course questionnaires were entered into the computer. The SPSS version 21 was used to analyze the data. Pretest data related to first $(n=26)$ and second $(n=39)$ intakes of medical students were merged, and similarly, posttest data of two intakes were also merged. Participants' strongly agree and agree and strongly disagree and disagree responses were pooled for analysis purpose. Their neutral responses were considered as such.
Missing responses were merged with disagree responses. Besides frequency distribution, we used $3 \times 2$ and $2 \times 2$ contingency tables for comparing data. Nonparametric $\chi^{2}$ test was used for comparing pre- (Group 1) and posttest (Group 2) responses of medical students. $P$-value $\leq 0.05$ was considered significant.

\section{Ethical considerations}

The research protocol was submitted to the ethics committee of the NCCAM, Riyadh and Majmaah University, and both committees approved the protocol. The Institutional Review Board number is NCCAM-5 vide dated $6.2 .1435 \mathrm{H}$ corresponding to Gregorian December 10, 2013.

\section{Results \\ General attitudes toward CAM}

The mean age of participants was $21.13 \pm 0.97$ (range $=7$, minimum and maximum age $=20$ and 27 , respectively). Medical students' general attitudes toward CAM revealed the following statistically significant results when their pre- and posttest responses were compared (Table 1): 1) participants disagreed that CAM is a threat to public health $\left.\left(\chi^{2}=6.46, d f=2, P=0.039\right) ; 2\right)$ according to medical students' views, health care providers should be able to advise their patients about commonly used CAM therapies $\left(\chi^{2}=7.69, d f=2, P=0.013\right)$; and 3$)$ they opined that CAM practices need to be included in their medical school curriculum $\left(\chi^{2}=7.52, d f=2, P=0.023\right)$. However, the rest of pre- and posttest responses related to other questions did change in the direction of favorable attitudes but without statistical significance.

\section{Barriers against CAM use}

According to participants' perceptions, several significant barriers to CAM use in western world were medical school concerns about legal problems $\left(\chi^{2}=13.75, d f=2, P=0.001\right)$, lack of both competent CAM providers $\left(\chi^{2}=14.64, d f=2\right.$, $P=0.0006)$ and appropriate equipment $\left(\chi^{2}=9.04, d f=2\right.$, $P=0.011)$, and being too time consuming $\left(\chi^{2}=5.998, d f=2\right.$, $P=0.049$ ) (Table 2). As regards other barriers including lack of evidence for practices, lack of staff training, and lack of reimbursement, there was a trend in the direction of agree responses with no statistical significance.

\section{Health worldview/framework and personal health views}

In response to what primary worldview or framework guides their personal health views, majority of participants (78.5\%) 
Table I General attitudes toward CAM

\begin{tabular}{|c|c|c|c|c|c|c|c|}
\hline \multirow[t]{3}{*}{ Item I questions } & \multicolumn{3}{|c|}{ Pretest - Group I } & \multicolumn{3}{|c|}{ Posttest - Group 2} & \multirow{3}{*}{$\begin{array}{l}\text { Exact } \\
P \text {-value }\end{array}$} \\
\hline & \multirow{2}{*}{$\frac{\mathrm{A}}{\text { No }(\%)}$} & \multirow{2}{*}{$\frac{\mathbf{N}}{\text { No (\%) }}$} & \multirow{2}{*}{$\frac{D}{\text { No }(\%)}$} & \multirow{2}{*}{ A } & \multirow{2}{*}{ No (\%) } & \multirow{2}{*}{$\frac{\text { D }}{\text { No }(\%)}$} & \\
\hline & & & & & & & \\
\hline $\begin{array}{l}\text { I. Clinical care should integrate the best of conventional } \\
\text { and CAM practices }\end{array}$ & $42(64.6)$ & $20(30.8)$ & $3(4.6)$ & $49(75.4)$ & $12(18.5)$ & $4(6.1)$ & 0.26 \\
\hline $\begin{array}{l}\text { 2. CAM includes ideas and methods from which conventional } \\
\text { medicine could benefit }\end{array}$ & $45(69.2)$ & $17(26.2)$ & $3(4.6)$ & $47(73.3)$ & $12(18.5)$ & $6(9.2)$ & 0.38 \\
\hline $\begin{array}{l}\text { 3. While we need to be cautious in our claims, a number } \\
\text { of CAM approaches hold promise for treatment of } \\
\text { symptoms, conditions, and/or diseases }\end{array}$ & $31(47.7)$ & $30(46.2)$ & $4(6.1)$ & $27(4 I .6)$ & $32(49.2)$ & $6(9.2)$ & 0.69 \\
\hline 4. The results of CAM are in most cases due to a placebo effect & $20(30.8)$ & $20(30.8)$ & $25(38.4)$ & $22(33.9)$ & $19(29.2)$ & $24(36.9)$ & 0.93 \\
\hline $\begin{array}{l}\text { 5. CAM therapies not tested in a scientific manner should be } \\
\text { discouraged }\end{array}$ & $31(47.7)$ & $26(40.0)$ & $8(12.3)$ & $37(56.9)$ & $21(32.3)$ & $7(10.8)$ & 0.57 \\
\hline $\begin{array}{l}\text { 6. While a few CAM approaches may have limited health } \\
\text { benefits, they have no true impact on treatment of } \\
\text { symptoms, conditions, and/or diseases }\end{array}$ & $24(36.9)$ & $18(27.7)$ & $23(35.4)$ & $22(33.8)$ & $23(35.4)$ & $20(30.8)$ & 0.64 \\
\hline 7. $C A M$ is a threat to public health & $18(27.7)$ & $15(23.1)$ & $32(49.2)$ & $24(36.9)$ & $23(35.4)$ & $18(27.7)$ & $0.039 *$ \\
\hline $\begin{array}{l}\text { 8. I hope to have some CAM practices available to patients } \\
\text { in my practice or referral network }\end{array}$ & $37(56.9)$ & $19(29.2)$ & $9(13.9)$ & $45(69.2)$ & $10(15.4)$ & $10(15.4)$ & 0.16 \\
\hline $\begin{array}{l}\text { 9. Health professionals should be able to advise their } \\
\text { patients about commonly used CAM methods }\end{array}$ & $35(53.8)$ & $19(29.3)$ & II (I6.9) & $50(76.9)$ & $10(15.4)$ & $5(7.7)$ & $0.013 *$ \\
\hline 10. CAM practices should be included in my school's curriculum & $39(60.0)$ & $21(32.3)$ & $5(7.7)$ & $51(78.5)$ & $8(12.3)$ & $6(9.2)$ & $0.0233 *$ \\
\hline $\begin{array}{l}\text { II. Knowledge about CAM is important to me as a student/ } \\
\text { future practicing health professional }\end{array}$ & 50 (76.9) & $13(20.0)$ & $2(3.1)$ & 49 (75.4) & $8(12.3)$ & $8(12.3)$ & 0.09 \\
\hline
\end{tabular}

Note: *Significant.

Abbreviations: CAM, complementary and alternative medicine; A, agree; N, neutral; D, disagree; No, number.

informed that combination of western biomedicine and traditional Chinese medicine directs their health understandings (Figure 1).

\section{Sources of CAM information}

The participants observed that their most important sources of CAM information were peer professionals, scientific journals, mass media, and Internet (Figure 2).

\section{Views about CAM as a practitioner}

Medical practitioners tend to have variable views regarding use of CAM therapies (Table 3). According to this survey, participants' responses to question number $1,5,9,12,14$, and 16 (Table 3) were statistically significant between their pre- and posttest views. Students disagreed that it is ethical for practitioners to advise CAM therapies to patients that involve the use of subtle energy fields in and around the body for medical purposes $\left(\chi^{2}=9.53, d f=2, P=0.0085\right)$. They also strongly disagreed with the statement that it is irresponsible for practitioners to recommend acupuncture to patients with conditions like chemotherapy-related nausea and vomiting or headache $\left(\chi^{2}=9.28, d f=2, P=0.0096\right)$. Furthermore, participants agreed strongly that patients whose practitioners are knowledgeable of multiple medical systems and CAM

Table 2 Barriers to use of CAM practices in western medical settings

\begin{tabular}{|c|c|c|c|c|c|c|c|}
\hline \multirow[t]{3}{*}{ Item 2 questions } & \multicolumn{3}{|c|}{ Pretest - Group I } & \multicolumn{3}{|c|}{ Posttest - Group 2} & \multirow{3}{*}{$\begin{array}{l}\text { Exact } \\
P \text {-value }\end{array}$} \\
\hline & $\mathbf{A}$ & $\mathbf{N}$ & D & $\mathbf{A}$ & $\mathbf{N}$ & D & \\
\hline & No (\%) & No (\%) & No (\%) & No (\%) & No (\%) & No (\%) & \\
\hline I. Lack of evidence for practices & $43(66.1)$ & $16(24.6)$ & $6(9.3)$ & $50(76.9)$ & II (I6.9) & $4(6.2)$ & 0.396 \\
\hline 2. Institutional concerns about legal issues & $32(49.2)$ & $25(38.5)$ & $8(12.3)$ & $49(75.5)$ & $7(10.7)$ & $9(13.8)$ & $0.00 I^{*}$ \\
\hline 3. Unavailability of credentialed providers & $25(38.5)$ & $34(52.2)$ & $6(9.3)$ & $46(70.8)$ & $14(2 \mid .5)$ & $5(7.7)$ & $0.0006^{*}$ \\
\hline 4. Lack of staff training & 37 (56.9) & $17(26.2)$ & II (I6.9) & 47 (7I.3) & $12(17.4)$ & $6(9.3)$ & $0.17 \mid$ \\
\hline 5. Lack of reimbursement & $26(40.0)$ & $30(46.2)$ & $9(13.8)$ & $31(47.7)$ & $26(40.0)$ & $6(9.3)$ & 0.424 \\
\hline 6. Lack of appropriate equipment & $28(43.1)$ & $16(24.6)$ & $21(32.3)$ & $45(69.2)$ & $9(13.8)$ & II (I6.9) & $0.01 I^{*}$ \\
\hline 7. Too time consuming & $20(30.8)$ & $26(40.0)$ & $19(29.2)$ & $31(47.7)$ & $14(2 \mid .5)$ & $20(30.8)$ & $0.049 *$ \\
\hline
\end{tabular}

Note: *Significant.

Abbreviations: CAM, complementary and alternative medicine; A, agree; N, neutral; D, disagree; No, number. 

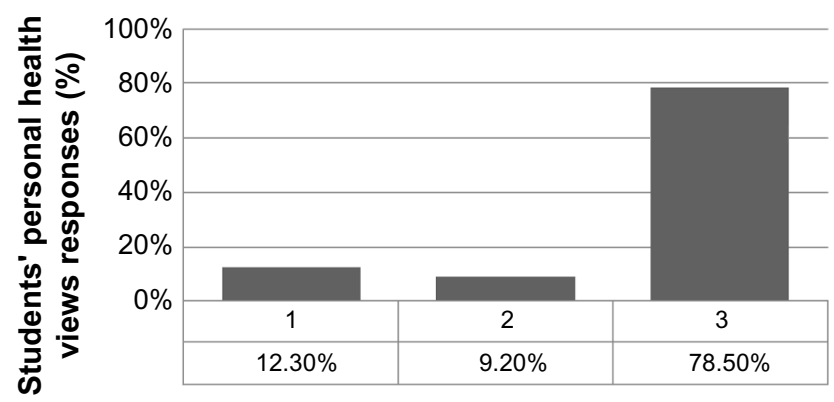

Figure I Distribution of students' primary worldview or framework guides by their personal health views (pretest responses only).

Notes: Personal health views:I, Western biomedicine; 2, traditional Chinese medicine; 3 , combination of the two.

practices, in addition to conventional medicine, do better than those whose practitioners are only familiar with conventional medicine $\left(\chi^{2}=6.19, d f=2, P=0.045\right)$. Students' response rate increased significantly posttest regarding improved outcomes associated with strong relationship between patient and practitioner, a kind of therapeutic intervention $\left(\chi^{2}=9.32, d f=2\right.$, $P=0.009$ ). Furthermore, medical students agreed significantly that counseling on nutrition by a physician is associated with the prevention of chronic diseases $\left(\chi^{2}=8.158, d f=2\right.$, $P=0.016$ ). Medical students viewed that delivery of better care to patients is strongly associated with those practitioners who strive to understand themselves than those who do not $\left(\chi^{2}=7.259, d f=2, P=0.0265\right)$. Students' responses related to the rest of questions improved positively but without achieving statistical significance.

\section{Health care pathways}

When participants' responses to which of the following components influence, the most or the least, to health care

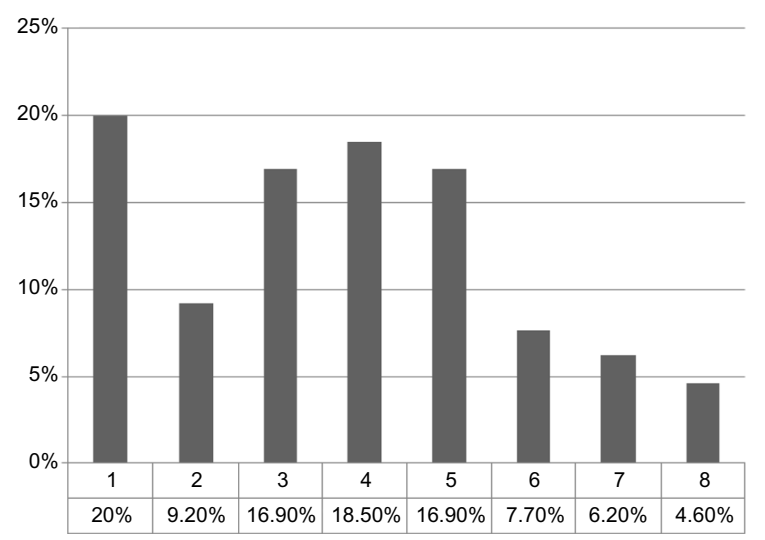

Figure 2 Distribution of students' sources of information about CAM (pretest responses only).

Notes: Sources of information about CAM: I, peer professionals; 2, other health care providers; 3 , various journals; 4 , mass media; 5 , Internet; 6 , course work; 7, referrals; 8, apprentice with healers.

Abbreviation: CAM, complementary and alternative medicine. approaches were analyzed, none of them was significantly associated with health care models: spiritual and religious beliefs $\left(\chi^{2}=1.88, d f=1, P=0.169\right)$, knowledge of CAM $\left(\chi^{2}=1.14, d f=1, P=0.285\right)$, cultural values $\left(\chi^{2}=0.033, d f=1\right.$, $P=0.856)$, personal experience $\left(\chi^{2}=0.148, d f=1, P=0.669\right)$, and research and evidence $\left(\chi^{2}=2.426, d f=1, P=0.119\right)$ (Figure 3).

\section{Public views about health and healing}

People's views about health and healing were significantly supported by student participants in the following areas (Table 4): connectivity between social stress and development of physical diseases $\left(\chi^{2}=12.255, d f=2, P=0.0022\right)$, reasonable discussion with patients about their health is associated with improvement in patients' health $\left(\chi^{2}=7.515\right.$, $d f=2, P=0.0233)$, and practitioners' time voluntarily spent in serving underserved communities $\left(\chi^{2}=7.004, d f=2\right.$, $P=0.0301)$. With regard to other health and healing areas, there was a favorable trend but without achieving statistical significance.

\section{Participants' responses to additional questions}

In response to three additional questions, the participants reported the following (a mix of pre- and post-exposure): 1) Spiritual and religious beliefs are integral part of complementary and alternative therapies, and hence, there needs to be special focus on the cultural belief system when faculty is in the process of developing CAM curriculum and teaching and instructing on such topics of great significance to the medical students and the community. 2) None of the participants had formal training in CAM in the past, but they reported to have frequent discussion on local CAM products among community members, and therefore, they suggested that teaching of CAM therapies must involve global view in general but local context in particular with regulation of CAM practices supported by legislation. 3) At global level, the use of CAM modalities is on the rise, and simultaneously, practitioners frequently encounter patients who take both CAM and modern medications, and thus, all medical schools should integrate CAM course in their curriculum in Saudi Arabia and other Gulf countries. These summarized views of participants reverberate with the perceptions of medical students, allied students, and professionals around the world. ${ }^{1,2,17,21,24,25,27,28,43}$

\section{Discussion}

According to this study, the participants reported that CAM is not a threat to public health, reflecting a positive attitude 
Table 3 Statements relate to views you may have as a practitioner

\begin{tabular}{|c|c|c|c|c|c|c|c|}
\hline \multirow[t]{3}{*}{ Item I 2 questions } & \multicolumn{3}{|c|}{ Pretest - Group I } & \multicolumn{3}{|c|}{ Posttest - Group 2} & \multirow{3}{*}{$\begin{array}{l}\text { Exact } \\
P \text {-value }\end{array}$} \\
\hline & \multirow{2}{*}{$\begin{array}{l}\text { A } \\
\text { No (\%) }\end{array}$} & \multirow{2}{*}{$\frac{N}{\text { No (\%) }}$} & \multirow{2}{*}{$\frac{D}{\text { No (\%) }}$} & \multirow{2}{*}{$\frac{A}{\text { No (\%) }}$} & \multirow{2}{*}{$\begin{array}{l}\mathbf{N} \\
\text { No (\%) }\end{array}$} & \multirow{2}{*}{$\frac{D}{\text { No (\%) }}$} & \\
\hline & & & & & & & \\
\hline $\begin{array}{l}\text { I. It is ethical for practitioners to recommend therapies to patients } \\
\text { that involve the use of subtle energy fields in and around the body } \\
\text { for medical purposes (eg, Reiki, healing touch, therapeutic touch) }\end{array}$ & $42(64.6)$ & $19(29.2)$ & $4(6.2)$ & $38(58.5)$ & II (I6.9) & $16(24.6)$ & $0.0085 *$ \\
\hline $\begin{array}{l}\text { 2. Practitioners should avoid recommending botanical medicines } \\
\text { based on observations of long-term use in other cultures and } \\
\text { systems of healing because such evidence is not based on large } \\
\text { randomized controlled trials }\end{array}$ & 35 (53.9) & $22(33.8)$ & $8(12.3)$ & $40(61.5)$ & $17(26.2)$ & $8(12.3)$ & 0.614 \\
\hline $\begin{array}{l}\text { 3. Practitioners should warn patients to avoid using botanical medicines } \\
\text { (herbs) and dietary supplements until they have undergone rigorous } \\
\text { testing such as is required for any pharmaceutical drug }\end{array}$ & 35 (53.9) & $21(32.3)$ & $9(13.8)$ & $43(66.1)$ & $14(2 \mid .6)$ & $8(12.3)$ & 0.319 \\
\hline $\begin{array}{l}\text { 4. Massage therapy often makes patients "feel" better temporarily } \\
\text { but does not lead to objective improvement in long-term } \\
\text { outcomes for patients }\end{array}$ & $33(50.9)$ & $21(32.3)$ & II (I6.8) & $42(64.6)$ & II (I6.9) & $12(18.5)$ & 0.119 \\
\hline $\begin{array}{l}\text { 5. It is irresponsible for practitioners to recommend acupuncture } \\
\text { to patients with conditions like chemotherapy-related nausea } \\
\text { and vomiting or headache }\end{array}$ & $35(53.9)$ & $24(36.9)$ & $6(9.2)$ & $34(52.4)$ & $13(20.0)$ & I8 (27.6) & $0.0096 *$ \\
\hline $\begin{array}{l}\text { 6. Information obtained by research methods other than } \\
\text { randomized controlled trials has little value to practitioners }\end{array}$ & $29(44.6)$ & $24(36.9)$ & $12(18.5)$ & $39(60.0)$ & $12(18.5)$ & 14 (2I.5) & 0.0600 \\
\hline $\begin{array}{l}\text { 7. It is not desirable for a practitioner to take therapeutic advantage } \\
\text { of the placebo effect }\end{array}$ & $30(46.2)$ & $24(36.9)$ & II (I6.9) & $35(53.8)$ & $21(32.3)$ & $9(13.9)$ & 0.675 \\
\hline 8. Healing is not possible when a disease is incurable & $30(46.2)$ & $21(32.3)$ & $14(2 \mid .5)$ & $34(52.4)$ & $19(29.2)$ & $12(18.4)$ & 0.777 \\
\hline $\begin{array}{l}\text { 9. Patients whose practitioners are knowledgeable of multiple } \\
\text { medical systems and complementary and alternative practices, in } \\
\text { addition to conventional medicine, do better than those whose } \\
\text { practitioners are only familiar with conventional medicine }\end{array}$ & $35(53.9)$ & $21(32.3)$ & $9(13.9)$ & $48(73.8)$ & $10(15.4)$ & $7(10.8)$ & $0.045^{*}$ \\
\hline $\begin{array}{l}\text { 10. Practitioners knowledgeable of multiple medical systems and } \\
\text { complementary and alternative practices (eg, Chinese, ayurveda, } \\
\text { osteopathic, homeopathic, naturopathic), in addition to } \\
\text { conventional medicine, generate improved patient satisfaction }\end{array}$ & $44(66.7)$ & $15(23.1)$ & $6(9.2)$ & $45(69.2)$ & $13(20.0)$ & $7(10.8)$ & 0.891 \\
\hline $\begin{array}{l}\text { II. Practitioners who strive to understand themselves generate } \\
\text { improved patient satisfaction }\end{array}$ & $38(58.5)$ & $19(29.2)$ & $8(12.3)$ & $49(75.4)$ & II (I6.9) & $5(7.7)$ & 0.121 \\
\hline $\begin{array}{l}\text { 12. A strong relationship between patient and practitioner is an } \\
\text { extremely valuable therapeutic intervention that leads to } \\
\text { improved outcomes }\end{array}$ & $37(56.9)$ & $20(30.8)$ & $8(12.3)$ & $53(81.5)$ & $8(12.3)$ & $4(6.2)$ & $0.009 *$ \\
\hline $\begin{array}{l}\text { 13. Practitioners who model a balanced lifestyle (eg, attending } \\
\text { to their own health, social, family, and spiritual needs, as well as } \\
\text { interests beyond medicine) generate improved patient satisfaction }\end{array}$ & $39(60.0)$ & I8 (27.7) & $8(12.3)$ & $51(78.5)$ & $9(13.8)$ & $5(7.7)$ & 0.07 \\
\hline $\begin{array}{l}\text { 14. Counseling on nutrition should be a major role of the } \\
\text { practitioner toward the prevention of chronic disease }\end{array}$ & $37(56.9)$ & $23(35.4)$ & $5(7.7)$ & $50(76.9)$ & $9(13.9)$ & $6(9.2)$ & $0.016^{*}$ \\
\hline $\begin{array}{l}\text { 15. Quality of life measures are of equal importance } \\
\text { as disease-specific outcomes in research }\end{array}$ & $38(58.5)$ & $21(32.3)$ & $6(9.2)$ & $34(52.3)$ & $20(30.8)$ & II (I6.9) & 0.423 \\
\hline $\begin{array}{l}\text { 16. Practitioners who strive to understand themselves provide } \\
\text { better care than those who do not }\end{array}$ & $32(49.2)$ & $22(33.9)$ & II (I6.9) & $47(72.3)$ & $12(18.5)$ & $6(9.2)$ & $0.0265^{*}$ \\
\hline 17. Instilling hope in patients is a practitioner's duty & $35(53.9)$ & $19(29.2)$ & II (I6.9) & $47(72.3)$ & $12(18.5)$ & $6(9.2)$ & 0.0903 \\
\hline
\end{tabular}

Note: *Significant.

Abbreviations: A, agree; N, neutral; D, disagree; No, number.

toward CAM practices, ${ }^{10}$ but this finding is inconsistent with other researchers. ${ }^{17}$ Generally, CAM treatment modalities are safe; there are potential dangers in special circumstances. ${ }^{13}$ Though costs of CAM therapies are not explored in this study, there is converging evidence that they are highly costeffective and cost saving, and therefore, the treatment costs are relatively low. ${ }^{12,13}$ Therefore, the CAM modalities and health systems are easily accessible to public health needs at a macro social level ${ }^{52}$ including poor patients and underserved communities who are unlikely to pay high costs of modern medications. ${ }^{53}$ Furthermore, medical students supported the notion that physicians should be able to advise their patients about commonly used CAM therapies, drug interactions, and efficacy issues consistent with other studies. ${ }^{46}$ In the 


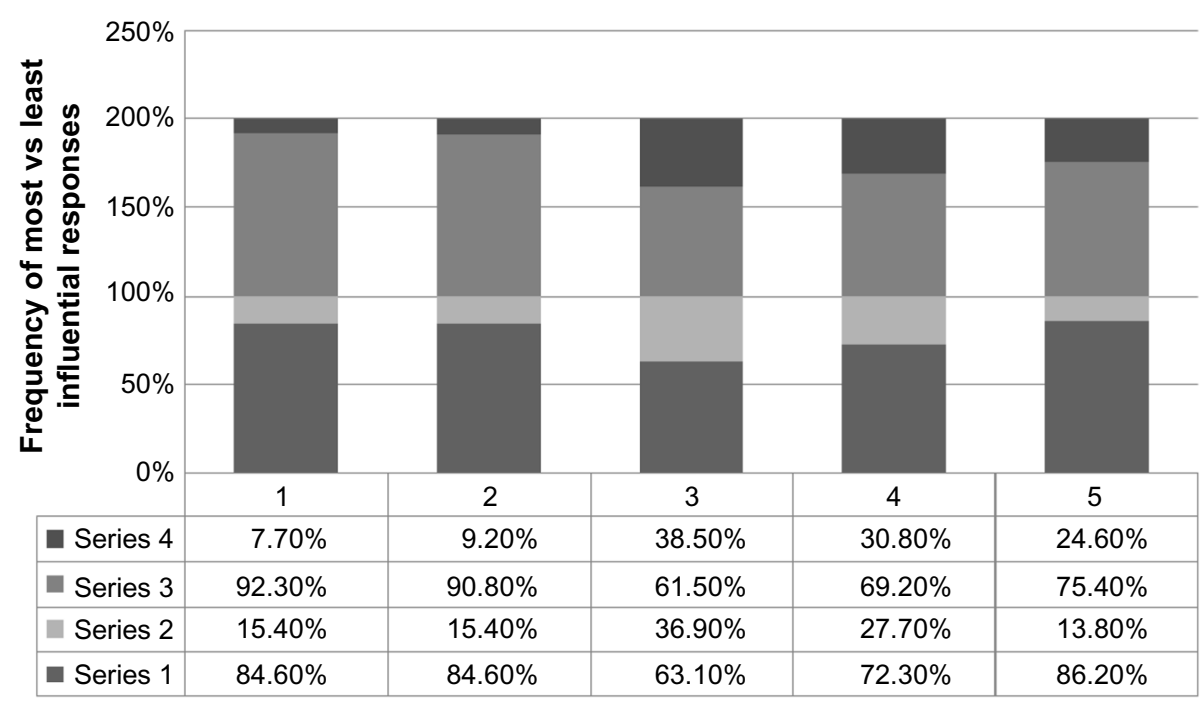

Figure 3 Comparison of contribution to participants' pre-(series I and 2) and posttest (series 3 and 4 ) (most vs least influential, respectively) responses by five approaches to health care.

Notes: Participants' responses by approaches to health care: I, spiritual and religious beliefs; 2, knowledge of CAM; 3, cultural values; 4, personal experience; 5 , research and evidence.

Abbreviation: CAM, complementary and alternative medicine.

Saudi context, the commonly used and supported CAM therapies include cupping (hijama), cautery, recitation from holy Quran, acupuncture, herbal preparations, apitherapy (use of honey and bee products), camel urine, aromatherapy, massage, biofeedback, therapeutic touch, and exercise, although there are many forms of CAM interventions used worldwide. ${ }^{1-5,7-9}$ Notably, most of medical students expressed that CAM course needs to be integrated into their medical school curriculum, and this trend is consistent with other studies. ${ }^{8,54,55}$ The long-term implications of this finding are many, including CAM capacity building in relation to clinical practice, research, teaching, and training.
According to many studies, the barriers against integration of CAM curriculum and use of CAM therapies exist across the world. ${ }^{22,23,56}$ In the context of western medical settings, the present study reported a number of barriers, including legal issues raised by medical schools and institutions, relative lack of competent CAM providers, lack of appropriate equipment, and CAM therapies being too time consuming, and these findings are compatible with other western studies. ${ }^{22,23,57}$ According to this research, although other barriers including lack of evidence for practices, lack of staff training, and lack of reimbursement did not achieve statistically significant association with participants' views,

Table 4 Statement of people's views about health and healing

\begin{tabular}{|c|c|c|c|c|c|c|c|}
\hline \multirow[t]{3}{*}{ Item I 6 questions } & \multicolumn{3}{|c|}{ Pretest - Group I } & \multicolumn{3}{|c|}{ Posttest - Group 2} & \multirow{3}{*}{$\begin{array}{l}\text { Exact } \\
\text { P-value }\end{array}$} \\
\hline & \multirow{2}{*}{$\frac{A}{\text { No }(\%)}$} & \multirow{2}{*}{$\frac{\mathbf{N}}{\text { No (\%) }}$} & \multirow{2}{*}{$\frac{\text { D }}{\text { No (\%) }}$} & \multirow{2}{*}{$\frac{A}{\text { No }(\%)}$} & \multirow{2}{*}{$\frac{\mathbf{N}}{\text { No (\%) }}$} & \multirow{2}{*}{$\frac{\text { D }}{\text { No (\%) }}$} & \\
\hline & & & & & & & \\
\hline I. Many health problems are related to spiritual factors & $42(64.6)$ & II (I6.9) & $12(18.5)$ & $46(70.8)$ & $9(13.8)$ & $10(15.4)$ & 0.754 \\
\hline 2. There is a connection between social stress and physical illness & $4 I(63.1)$ & II (I6.9) & $13(20.0)$ & $58(89.2)$ & $3(4.6)$ & $4(6.2)$ & $0.0022 *$ \\
\hline 3. The link between social factors and disease is overemphasized & $34(52.3)$ & $21(32.3)$ & $10(15.4)$ & $35(53.8)$ & $23(35.4)$ & $7(10.8)$ & 0.728 \\
\hline $\begin{array}{l}\text { 4. Determining what the patient feels, believes, or knows about } \\
\text { his or her health is essential to the practitioner in taking steps } \\
\text { to improve the patient's health }\end{array}$ & $34(52.3)$ & $17(26.2)$ & $14(2 \mid .5)$ & $48(73.8)$ & $12(18.5)$ & $5(7.7)$ & $0.0233^{*}$ \\
\hline $\begin{array}{l}\text { 5. Practitioners should volunteer some time to help underserved } \\
\text { communities }\end{array}$ & $37(56.9)$ & $23(35.4)$ & $5(7.7)$ & $47(72.3)$ & $10(15.4)$ & $8(12.3)$ & $0.0301 *$ \\
\hline $\begin{array}{l}\text { 6. The environment (pesticides, growth hormones/food additives, } \\
\text { power plants) has a greater impact on health and disease } \\
\text { than is currently acknowledged }\end{array}$ & 37 (56.9) & I 8 (27.7) & $10(15.4)$ & $43(66.1)$ & $17(26.2)$ & $5(7.7)$ & 0.342 \\
\hline 7. The body has an innate ability to heal itself & $44(67.7)$ & II (16.9) & $10(15.4)$ & $43(66.1)$ & $18(26.7)$ & $4(6.2)$ & 0.118 \\
\hline
\end{tabular}

Note: *Significant.

Abbreviations: A, agree; N, neutral; D, disagree; No, number. 
there were identifiable trends in the direction of agree responses expressed by medical students. Notably, these barriers are commonly reported in other studies..$^{22,23,37,57}$ It is questionable whether or not similar barriers against use of CAM interventions apply to Saudi medical settings because participants' responses relate to western medical settings. A review of relevant literature in Arabian Gulf countries found some studies that addressed multiple perspectives of CAM therapies, but only few discussed the issue of barriers against the use of CAM modalities. ${ }^{37}$ The research team suggests that KAP studies should also include exploration of barriers against use of CAM therapies in Middle East countries including KSA.

Besides two frameworks that guide personal health development and its understanding, another worldview is a hybrid model, IM, which focuses on a holistic approach ${ }^{58}$ that benefits patients and promotes health of the population. According to this research, most medical students observed that integrated medical system guides their personal health views, which is consistent with other studies. ${ }^{58,59}$ Integrated medicine approaches are used in the management of patients who present with diverse, chronic diseases and health problems. ${ }^{60}$ The present study quite rightly supported the integrated model of care associated with better outcomes and good quality of life. ${ }^{58}$ Medical students tend to collect information on CAM from multiple sources as revealed in this study. Accordingly, medical students reported that their most important sources of CAM information were peers, scientific journals, media, and Internet, and these results are partially consistent with other reports. ${ }^{30}$ Predictably, this CAM info-source scenario would change in future when CAM course will be integrated into main curriculum of all medical schools in KSA.

According to this survey, medical students reported variable views regarding use of CAM therapies. Students strongly disagreed with the statement that it is ethical for practitioners to advise CAM therapies to patients that especially involve the use of subtle energy fields in and around the body for medical purposes, which is incompatible with international data ${ }^{61}$ could be attributed to lack of knowledge in biomagnetic field therapies. Healing touch, therapeutic touch (biomagnetic touch), massage, Yoga, moxibustion, laser acupuncture, homeopathy, and Reiki are some of the CAM modalities that use the concept of energy biofields in ameliorating various diseases. ${ }^{62,63}$ These CAM therapies initially met ethics and regulatory challenges, ${ }^{64}$ but this scenario is substantially changed. CAM therapies used worldwide are now supported by guidelines. ${ }^{16,65,66}$ Though energy medicine has its proponents and opponents, the relevant energy biomagnetic therapies are increasingly recognized with evidence-based data to be used in a variety of diseases with better outcome. ${ }^{61-63}$ The participants also strongly disagreed with the statement that it is irresponsible for practitioners to recommend acupuncture to patients with conditions like chemotherapy-related nausea and vomiting or headache, and this is compatible with other international randomized controlled trials and systematic reviews. ${ }^{67}$ Acupuncture, in its different invasive and noninvasive forms including laser acupuncture, is recommended either as an adjunct or as an alternative in various conditions including chemotherapyinduced nausea and vomiting, headache, migraine, low back pain, and also in anesthesia practice. ${ }^{68,69}$

According to this survey, majority of participants agreed that patients whose practitioners have knowledge in multiple medical systems, CAM practices, and conventional medicine do better than those whose practitioners are only familiar with conventional medicine, and this view matches with international studies. ${ }^{8,17}$ In another way, physicians with vast medical knowledge and multiple skills could discuss with the patient a variety of disease-related issues and put forward more than one option to be accepted, the best one, by the patient, that would fit into patient-centered approach currently in vogue in CAM/IM. ${ }^{70-72}$ In the similar vein, medical students also attested to the fact that the improved outcome is strongly associated with professional relationship between patient and practitioner, which is considered a kind of therapeutic intervention. ${ }^{73}$ Literature suggests that the development and sustainment of healthy rapport with patient throughout the process of treatment and based on effective communication is an ideal philosophy that underlies good adherence, better outcome, and improved quality of life of health consumers. ${ }^{74,75}$ Currently, nutrition has achieved an exceptional place in CAM therapies, mainly for cancer survivors. ${ }^{76,77}$ In line with this therapeutic development, medical students agreed significantly that counseling on nutrition by a physician is associated with the prevention of chronic diseases. Consequently, nutrition counselors need to be available in medical settings at all levels. Dietary tips matching with needed lifestyle changes and chronic care model guidelines are the core intervention issues in the prevention of chronic diseases, related complications, disabilities, and mortality. ${ }^{76-78}$ Medical students viewed that delivery of better care to patients is strongly associated with those practitioners who themselves strive to understand than those who do not, which is supported by other researchers. ${ }^{79}$ The selfevaluation done by using self-evaluation tools, and negatively 
associated with stress and mediated by orientation to goals, ${ }^{80}$ is reported to provide insights into one's competency gaps, that is, strengths and weaknesses, and consequently, practitioners need to improve their knowledge, clinical practice, research scholarship, and teaching and training skills. ${ }^{79,81}$ As a result, practitioners tend to not only improve their practice considerably but also provide benefit to patients who would otherwise opt for better health care. A note of caution is that physician's ability to self-assess is mostly inaccurate, and external assessment is preferred. ${ }^{79}$

Notably, participants' individual health pathways in terms of spiritual and religious beliefs, knowledge of CAM, cultural values, personal experience, and research and evidence did not contribute significantly to various approaches to health care, which is inconsistent with other studies. ${ }^{82-87}$ Notably, these approaches may collectively guide health care models; however, not supporting exclusively individual approach by medical students in this study is in line with the concept of multimodal/multifaceted strategy ${ }^{79,88}$ in the prevention, management, and rehabilitation of patient with simple-tocomplex diseases such as chronic pain, cancers, functional bowel disorders, stroke, and depression ${ }^{53,89-92}$ and in surgical applications. ${ }^{93}$

People at large have different views about health and healing, which is a program of IM..$^{82,86}$ According to this research, medical students supported the notion that social stress is related to the development of physical (and psychological) diseases. ${ }^{94}$ Evidently, overwhelming or aggregated stress over a period of time is reported to cause homeostatic changes in the body, ultimately leading to psychological and physical conditions, which are relieved by stress management methods and other CAM therapies including stress-coping strategies and provision of social supports. ${ }^{94,95}$ Patients' involvement (including caretakers and public) in discussion and shared decision making about their treatment on long- and shortterm bases, a recent trend and based on research evidence, is associated with improvement in patients' health, knowledge/ literacy, well-being and satisfaction, adherence, and outcome with good quality of life,,${ }^{96,97}$ and this view of people is also supported by the participants of the present study. This autonomous ideology, ethically sound, gives patients complete control on their health and health-related perspectives. ${ }^{96-98}$ The public demands that practitioners should voluntarily spend some time (4 hours per week) in serving underserved communities is also evidenced in this study, which invigorates morality and altruistic attitude of physicians and also helps not only in promoting the health of the poor population but also lessen their financial burden. ${ }^{99}$

\section{Limitations}

There are several significant limitations to this cross-sectional research. There were many statistically negative results but with positive trends in KAP of medical students in this survey. However, this means that after gaining some knowledge, medical students formed favorable attitude toward CAM practice. The research team suggests that in future, besides further simplifying questionnaire, teachers should focus additionally on those areas of CAM-KAP, which were not significantly changed following exposure of Majmaah University medical students to CAM course. This is a survey of second-year male medical students in one university, and hence, its results are not generalizable to female medical students and other universities in KSA. As regards female medical students' attitude toward CAM, inconsistent findings were reported across transatlantic countries, ${ }^{100-102}$ and researchers called for further intersex KAP studies on CAM. Similarly, the results may not be applicable to other health professionals such as nursing or dental students and third-, fourth-, or fifth-year students as their KAP tend to differ from first- and second-year students. ${ }^{8,49,73}$ First-year students, especially female, are reported to show more interest in, positive attitude toward, and personal use of CAM than second-/third-year students ${ }^{8,17,49,73,103}$ attributed to cohort effect ${ }^{73}$ and continuing exposure to orthodox medical training. ${ }^{49}$ We did not use any other test of significance because pre- and posttest data of individual participant were not aligned and individual participant's anonymity was preserved on pre- and posttest questionnaire. Overall, the preliminary results of this research should be interpreted cautiously. The strength of this study is that $100 \%$ of students filled out the questionnaire. Also, this survey makes some sense of Majmaah University medical students' responses regarding their improved general attitude, knowledge, and practice views about CAM, and possibly, their improved KAP of CAM may persist over the years of medical training. ${ }^{3}$

\section{Conclusion}

In summary, the preliminary findings of this survey are partially compatible with international data on medical students' KAP of CAM modalities, and CAM course tends to have positive impact on KAP of medical students of Majmaah University.

\section{Author contributions}

Abdullah MN Al-Bedah and Mohammed Othman AlRukban conceptualized the paper design. Naseem Akhtar Qureshi, Mohammed Abdullah Al Mansour, Mohamed KM Khalil, Ibrahim S Elsubai, Elsadiq Yousif Mohamed, 
Khalid Altohami Medani, Waqas Sami Mahmoud, Ahmed Tawfik El Olemy, Asim AH Khalil, Abdullah Almudaiheem, and Meshari Saleh Alqaed made the literature search and helped in analyzing the data. Naseem Akhtar Qureshi drafted the paper and all authors critically revised it a number of times.

\section{Acknowledgments}

The NCCAM supported this study. College of Medicine, Majmaah University distributed the questionnaires to two intakes of second-year medical students, collected the data, and entered in the computer for analysis. Teachers affiliated to NCCAM and Majmaah University developed CAM curriculum and delivered the course to medical students.

\section{Disclosure}

The authors report no conflicts of interest in this work.

\section{References}

1. Karff SE. Recognizing the mind/body/spirit connection in medical care. Virtual Mentor. 2009;11(10):788-792.

2. Haylock PJ. Advanced cancer: a mind-body-spirit approach to life and living. Semin Oncol Nurs. 2010;26(3):183-194.

3. Lie DA, Boker J. Comparative survey of complementary and alternative medicine (CAM) attitudes, use, and information-seeking behaviour among medical students, residents and faculty. BMC Med Educ. 2006;6:58.

4. Qureshi NA, Al-Bedah AM. Mood disorders and complementary and alternative therapies. Neuropsychiatr Dis Treat. 2013;9:639-658.

5. Ujala V, Rashmi S, Pankaj G, Samta G, Bhuvneshvar K. Allopathic vs ayurveda practices in tertiary care institutes of urban North India. Ind J Pharmacol. 2007;39:52-54.

6. Chiappelli F, Prolo P, Cajulis OS. Evidence-based research in complementary and alternative medicine I: history. Evid Based Complement Alternat Med. 2005;2(4):453-458.

7. Cramer H, Lauche R, Dobos G. Characteristics of randomized controlled trials of yoga: a bibliometric analysis. BMC Complement Altern Med. 2014;14:328.

8. Akan H, Izbirak G, Kaspar EC, et al. Knowledge and attitudes towards complementary and alternative medicine among medical students in Turkey. BMC Complement Altern Med. 2012;12:115.

9. Busse JW, Kulkarni AV, Badwall P, Guyatt GH. Attitudes towards fibromyalgia: a survey of Canadian chiropractic, naturopathic, physical therapy and occupational therapy students. BMC Complement Altern Med. 2008;8:24

10. Adrian F, Clare MG. Medical students' attitudes towards complementary and alternative medicine. J Complement Altern Med. 2003;9(2):275-284.

11. Liu J, Pei M, Zheng C, et al. A systems-pharmacology analysis of herbal medicines used in health improvement treatment: predicting potential new drugs and targets. Evid Based Complement Alternat Med. 2013;2013:17.

12. Herman PM, Poindexter BL, Witt CM, Witt CM, Eisenberg DM. Are complementary therapies and integrative care cost-effective? A systematic review of economic evaluations. BMJ. 2012;2:e001046.

13. WHO News: New alternative medicine guide launched amidst increasing reports of adverse reactions. Bull World Health Org. 2004;82(8):635-636.
14. Nahin RL, Barnes PM, Stussman BJ,Bloom B. Costs of complementary and alternative medicine (CAM) and frequency of visits to CAM practitioners: United States,2007. Natl Health Stat Report. 2009;18:1-14.

15. Davis MA, Weeks WB. The concentration of out-of-pocket expenditures on complementary and alternative medicine in the United States. Altern Ther Health Med. 2012;18:36-42.

16. Barnes PM, Bloom B, Nahin RL. Complementary and alternative medicine use among adults and children: United States, 2007. Natl Health Stat Report. 2008;12:1-23.

17. Halterman-Cox M, Sierpina VS, Sadoski M, Sanders C. CAM attitudes in first- and second-year medical students: a pre-and post-test course survey. Integr Med. 2009;7(6):34-42.

18. Wolsko P, Ware L, Kutner J, et al. Alternative/complementary medicine:wider usage than generally appreciated. J Altern Compelent Med. 2000;6:321-326.

19. Institute of Medicine of the National Academies. Complementary and Alternative Medicinein the United States. Washington, DC: National Academies Press; 2005.

20. Education and Training of Health Care Practitioners. The WhiteHouse Commission on Complementary and Alternative Medicine Policy; 2015. Available from: http://www.whccamp.hhs.gov/fr4.html. Accessed January 2, 2015.

21. Brokaw JJ, Tunnicliff G, Raess BU, Saxon DW. The teaching of complementary and alternative medicine in US medical schools: a survey of course directors. Acad Med. 2002;77(9):876-881.

22. Sierpina VS, Schneeweiss R, Frenkel MA, Bulik R, Maypole J. Barriers, strategies, and lessons learned from complementary and alternative medicine curricular initiatives. Acad Med. 2007;82(10):946-950.

23. Frenkel M, Arye EB. The growing need to teach about complementary and alternative medicine; questions and challenges. Acad Med. 2001;76:251-254.

24. Levine SM, Weber-Levine ML, Mayberry RM. Complementary and alternative medicalpractices: training, experience, and attitudes of a primary care medical schoolfaculty. JAm Board Fam Pract. 2003;16(4): 318-326.

25. Bhattacharya B. Programs in the United States with complementary and alternative medical education opportunities: an ongoing listing. J Altern Compl Med. 2000;6:77-90+Carlston M. The revolution in medical education: complementary medicine joins the curriculum. Healthcare Forum J. 1998;41(6):25-29.

26. Chaterji R, Tractenberg RE, Amri H, Lumpkin M, Amorosi SB, Haramati A. A largesamplesurvey of first- and second-year medical student attitudes toward complementaryand alternative medicine in the curriculum and in practice. Altern Ther Health Med. 2007; 13(1):30-35.

27. Elolemy AT, Al-Bedah AMN. Public knowledge, attitude and practice of complementary and alternative medicine in Riyadh region, Saudi Arabia. Oman Med J. 2012;27:20-26.

28. Al-Rowais N, Mohammad AG, Al-Rukban M, Abdulghani HM. Traditional healers in Riyadh region: reasons and health problems for seeking their advice. A household survey. J Altern Complement Med. 2010;16:199-204.

29. Al-Zahim AA, Al-Malki NY, Al-Abdulkarim FM, Al-Sofayan SA, Abunab HA, Abdo AA. Use of alternative medicine by Saudi liver disease patients attending a tertiary care center: prevalence and attitudes. Saudi J Gastroenterol. 2013;19:75-80.

30. Al-Bedah AMN, Elolemy AT, Khalil MKM. Knowledgeand attitude of health professionalsin Riyadh region, Saudi Arabia, toward complementary and alternative medicine. J Family Community Med. 2012;19(2):93-99.

31. Abdullah Al-Rowais N, Al Bedah AM, Khalil MK, et al. Knowledge and attitudes of primary care physicians towards complementary and alternative medicine in the Riyadh region, Saudi Arabia. Forsch Komplement Med. 2012;19:7-12.

32. Al-Bedah AM, Khalil MK, Elolemy AT, et al. The use of and out-ofpocket spending on complementary and alternative medicine in Qassim province, Saudi Arabia. Ann Saudi Med. 2013;33(3):282-289. 
33. Jazieh AR, Al Sudairy R, Abulkhair O, et al. Use of complementary and alternative medicine by patients with cancer in Saudi Arabia. J Altern Complement Med. 2012;18(11):1045-1049.

34. Gad A, Al-Faris E, Al-Rowais N, Al-Rukban M. Use of complementary and alternative medicine for children: a parents' perspective. Complement Ther Med. 2013;21(5):496-500.

35. Al-Faris EA, Al-Rowais N, Mohamed AG, et al. Prevalence and pattern of alternative medicine use:the results of a household survey. Ann Saudi Med. 2008;28:4-10.

36. Alkharfy KM. Community pharmacists' knowledge, attitudes and practices towards herbal remedies in Riyadh, Saudi Arabia. East Mediterr Health J. 2010;16(9):988-993.

37. Awad AI, Al-Ajmi S, Waheedi MA. Knowledge, perceptions and attitudes toward complementary and alternative therapies among Kuwaiti medical and pharmacy students. Med Princ Pract. 2012;21(4): 350-354.

38. Allam S, Moharam M, Alarfaj G. Assessing patients' preference for integrating herbal medicine within primary care services in Saud Arabia. J Evid Based Complement Altern Med. 2014;19(3):205-210.

39. Al-Rukban MO, AlBedah AM, Khalil MK, El-Olemy AT, Khalil AA Alrasheid MH. Status of complementary and alternative medicine in the curricula of health colleges in Saudi Arabia. Complement Ther Med. 2012;20(5):334-339

40. Subhose V, Srinivas P, Narayana A. Basic principles of pharmaceutical science in ayurveda. Bull Indian Inst Hist Med Hyderabad. 2005;35 83-92.

41. Tilburt JC, Kaptchuk TJ. Herbal Medicine Research and Global Health: An Ethical Analysis: Bull WHO. Available from: http://www.who.int/ bulletin/volumes/86/8/07-042820/en/. Accessed January 6, 2015.

42. Gogtay NJ, Bhatt HA, Dalvi SS, Kshirsagar NA. The use and safety of non-allopathic Indian medicines. Drug Safety. 2002;25:1005-1019.

43. Gawde SR, Shetty YC, Pawar DB. Knowledge, attitude, and practices toward ayurvedic medicine use among allopathic resident doctors: a cross-sectional study at a tertiary care hospital in India. Perspect Clin Res. 2013;4(3):175-180.

44. Majmaah University, Saudi Arabia. 2014. Available from: http:// mu.edu.sa/en/about/history. Accessed December 15, 2014.

45. Kligler B, Koithan M, Maizes V, et al. Competency-based evaluation tools for integrative medicine training in family medicine residency: a pilot study. BMC Med Educ. 2007;7:7

46. Pearson NJ, Chesney MA. The CAM education program of the national center for complementary and alternative medicine: an overview. Acad Med. 2007;82(10):921-926.

47. Lee MY, Benn R, Wimsatt L, et al. Integrating complementary and alternative medicine instruction into health professions education: organizational and instructional strategies. Acad Med. 2007;82(10): 939-945.

48. Schneider CD, Meek PM, Bell IR. Development and validation of IMAQ: integrative medicine attitude questionnaire. BMC Med Educ. 2003;3:5

49. Furnham A, McGill C. Medical students' attitudes about complementary and alternative medicine. J Altern Complement Med. 2003;9(2):275-284.

50. Kreitzer MJ, Mitten D, Harris I, Shandeling J. Attitudes toward CAM among medical, nursing, and pharmacy faculty and students: a comparative analysis. Altern Ther Health Med. 2002;8(6):44-47,50-53.

51. Griffith LE, Cook DJ, Guyatt GH, Charles CA. Comparison of open and closed questionnaire formats in obtaining demographic information from Canadian general internists. J Clin Epidemiol. 1999;52: 997-1005.

52. Gale N. The sociology of traditional, complementary and alternative medicine. Sociol Compass. 2014;8(6):805-822.

53. Bazargan M, Ani CO, Hindman DW, et al. Correlates of complementary and alternative medicine utilization in depressed, underserved African American and Hispanic patients in primary care settings. J Altern Complement Med. 2008;14(5):537-544.

54. Yildirim Y, Parlar S, Eyigor S, et al. An analysis of nursing and medical students' attitudes towards and knowledge of complementary and alternative medicine (CAM). JCN. 2010;19:1157-1166.
55. Alis O, Ganime S, Nuran B, Mumtaz MM, Nazan B, Isik B. An analysis of nursing and medical students' attitudes towards and knowledge of complementary and alternative medicine (CAM). JAltern Complement Med. 2007;13(9):1007-1010.

56. Fonfa AE. Patient perspectives: barriers to complementary and alternative medicine therapies create problems for patients and survivors. Integr Cancer Ther. 2007;6(3):297-300.

57. Yeo AS, Yeo JC, Yeo C, Lee CH, Lim LF, Lee TL. Perceptions of complementary and alternative medicine amongst medical students in Singapore - a survey. Acupunct Med. 2005;23(1):19-26.

58. Katherine K. What is Integrative Medicine? Experts Explore New Ways to Treat the Mind, Body, And spirit-All at the Same Time; 2015 Available from: http://www.webmd.com/a-to-z-guides/features/alternative-medicine-integrative-medicine. Accessed January 1, 2015.

59. Agbaje EO, Babatunde EO. A KAP study of the attitude and practice of traditional medicine in contemporary Nigerian community. Cent Afr J Med. 2005;51(5-6):58-62.

60. Tam WWS, Wong ELY, Wong FCY, Cheung AWL. Citation classics in the integrative and complementary medicine literature: 50 frequently cited articles. Eur J Integr Med. 2012;4(1):e77-e83.

61. Jain S, Mills PJ. Biofield therapies: helpful or full of hype? A best evidence synthesis. Int J Behav Med. 2010;17:1-16.

62. Eden D, Feinstein D. The Basic Grid Booklet; 2015. Available from: http://innersource.net/em/images/downloads/pdf_files/Basic_Grid_ Booklet-feb-2014.pdf. Accessed January 12, 2015.

63. Anderson JG, Taylor AG. Effects of healing touch in clinical practice: a systematic review of randomized clinical trials. J Holist Nurs. 2011; 29(3):221-228.

64. Ernst E, Cohen MH, Stone J. Ethical problems arising in evidence based complementary and alternative medicine. J Med Ethics. 2004;30:156-159.

65. CAMDOC. Model Guidelines for the Practice of Complementary Therapies (CAM) by Medical Doctors in the European Union; 2015. Available from: http://www.camdoc.eu/Pdf/Model\%20Guidelines\%20 CAM\%20Practice.pdf. Accessed January 10, 2015.

66. NCCAM. Clinical Practice Guidelines; 2015. Available from: http:// nccam.nih.gov/health/providers/clinicalpractice.htm. Accessed January 7 , 2015.

67. Lee A, Fan LTY. Stimulation of the wrist acupuncture point P6for preventing postoperative nausea and vomiting. Cochrane Database Syst Rev. 2009;3:CD003281.

68. Lee A, Chan S. Acupuncture and anaesthesia. Best Pract Res Clin Anaesthesiol. 2006;20(2):303-314.

69. Wang SM, Harris RE, Lin YC, Gan TJ. Acupuncture in 21st century anesthesia: is there a needle in the Haystack? Pain Med. 2013; 116:6.

70. Scholl I, Zill JM, Harter M, Dirmaier J. An integrative model of patientcenteredness - a systematic review and concept analysis. PLoS One. 2014;9(9):e107828.

71. Saunders PA, Tractenberg RE, Chaterji R, et al. Promoting self-awareness and reflection through an experiential mind-body skills course for first year medical students. Med Teach. 2007;29(8):778-784.

72. Elder W, Rakel D, Heitkemper M, et al. Using complementary and alternative medicine curricular elements to foster medical student self-awareness. Acad Med. 2007;82(10):951-955.

73. DeSylvia D, Stuber M, Fung CC, Bazargan-Hejazi S, Cooper E. The knowledge, attitudes and usage of complementary and alternative medicine of medical students. Evid Based Complement Altern Med. 2011;2011:5.

74. Bakić-Mirić NM, Bakić NM. Successful doctor-patient communication and rapport building as the key skills of medical practice. Med Biol. 2008;15(2):74-79.

75. Golin CE, Thorpe C, DiMatteo MR. Accessing the Patient's WorldPatient-Physician Communication about Psychosocial Issues; 2015. Available from: www.jblearning.com/samples/0763749613/49613 CH07.pdf. Accessed January 10, 2015.

76. Dixon S. Nutrition in complementary and alternative medicine. Semin Oncol Nurs. 2012;28(1):75-84. 
77. Whayne TF Jr, Maulik N. Nutrition and the healthy heart with an exercise boost. Can J Physiol Pharmacol. 2012;90(8):967-976.

78. Wagner EH, Austin BT, Davis C, Hindmarsh M, Schaefer J, Bonomi A. Improving chronic illness care: translating evidence into action. Health Aff. 2001;20(6):64-78.

79. Davis DA, Mazmanian PE, Fordis M, Van Harrison R, Thorpe KE, Perrier L. Accuracy of physician self-assessment compared with observed measures of competence. JAMA. 2006;296(9): 1094-1102.

80. Morris ML, Messal CB, Meriac JP. Core self-evaluation and goal orientation: understanding work stress. Human Res Dev Q. 2013;24: $35-62$.

81. AAPA. Physician Assistant's Competencies: A Self-Evaluation Tool. Available from: http://www.nccpa.net/pdfs/competencies $\% 20$ Self $\% 20$ Evaluation\%20Tool.pdf. Accessed January 9, 2015.

82. Rumun AJ. Influence of religious beliefs on healthcare practice. Int $J$ Educ Res. 2014;2(4):37-48.

83. Campinha-Bacote J. The process of cultural competence in the delivery of healthcare services: a model of care. $J$ Transcult Nurs. 2002;13:181-184

84. Entwistle VA, France EF, Wyke S, et al. How information about other people's personal experiences can help with healthcare decisionmaking: a qualitative study. Patient Educ Couns. 2011;85(3): e291-e298.

85. Sackett DL, Rosenberg WMC, Gray JAM, Haynes RB, Richardson WS. Evidence based medicine: what it is and what it isn't. BMJ. 1996;312:71-72.

86. Puchalski CM, Post SG, Sloan RP. Physicians and patients' spirituality. Virtual Mentor. 2009;11(10):804-815.

87. Johnson MB, Bertrand SW, Fermon B, Coleman JF. Pathways to healing: person-centered responses to complementary services. Glob Adv Health Med. 2014;3(1):8-16.

88. Kehlet H. Multimodal approach to postoperative recovery. Curr Opin Crit Care. 2009;15(4):355-358.

89. Rosenberg EI, Genao I, Chen I, et al. Complementary and alternative medicine use by primary care patients with chronic pain. Pain Med. 2008;9(8):1065-1072.

90. Mao JJ, Palmer SC, Straton JB, et al. Cancer survivors with unmet needs were more likely to use complementary and alternative medicine. J Cancer Surviv. 2008;2(2):116-124.

91. van Tilburg MAL, Palsson OS, Levy RL. Complementary and alternative medicine use and cost in functional bowel disorders: a six month prospective study in a large HMO. BMC Complement Altern Med. 2008;8:46.
92. Shah SH, Engelhardt R, Ovbiagele B. Patterns of complementary and alternative medicine use among United States stroke survivors. J Neurolog Sci. 2008;271(1-2):180-185.

93. Fleckenstein J, Baeumler PI, Gurschler C, et al. Acupuncture for post anaesthetic recovery and postoperative pain: study protocol for a randomised controlled trial. Trials. 2014;15:292.

94. Thoits PA. Stress and health: major findings and policy implications. J Hlth Social Behavior. 2010;51(S):S41-S53.

95. Adli M. Urban Stress and Mental Health; 2015. Available from: http:// files.lsecities.net/files/2011/11/2011_chw_4030_Adli.pdf. Accessed January 12, 2015.

96. Joosten EA, DeFuentes-Merillas L, de Weert GH, Sensky T, van der Staak CP, de Jong CA. Systematic review of the effects of shared decision-making on patient satisfaction, treatment adherence, and health status. Psychother Psychosom. 2008;77:219-226.

97. Wilson SR, Strub P, Buist AS, et al; Better Outcomes of Asthma Treatment (BOAT) Study Group. Shared treatment decision making improves adherence and outcomes in poorly controlled asthma. Am J Respir Crit Care Med. 2010;181:566-577.

98. Coulter A, Parsons S, Askham J. Where are the Patients IndecisionMaking About Their Own Care?; 2015. Available from: http://www. who.int/management/general/decisionmaking/WhereArePatientsinDecisionMaking.pdf. Accessed January 14, 2015.

99. Goldstein AO, Calleson D, Curtis P, et al. Community service by North Carolina family physicians. J Am Board Fam Pract. 2005; 18:48-56.

100. Smith BW, Dalen J, Wiggins KT, Christopher PJ, Bernard JF, Shelley BM. Who is willing to use complementary and alternative medicine. Explore. 2008;4:359-367.

101. Chez RA, Jonas WB, Crawford C. A survey of medical students' opinions about complementary and alternative medicine. Am J Obstet Gynecol. 2001;185(3):754-757.

102. Greenfield SM, Brown R, Dawlatly SL, Reynolds JA, Roberts S, Dawlatly RJ. Gender differences among medical students in attitudes to learning about complementary and alternative medicine. Complement Therapies Med. 2006;14(3):207-212.

103. Greenfield SM, Innes MA, Allan TF, Wearn AM. First year medical students' perceptions and use of complementary and alternative medicine. Complement Therapies Med. 2002;10(1):27-32.
Advances in Medical Education and Practice

\section{Publish your work in this journal}

Advances in Medical Education and Practice is an international, peerreviewed, open access journal that aims to present and publish research on Medical Education covering medical, dental, nursing and allied health care professional education. The journal covers undergraduate education, postgraduate training and continuing medical education

\section{Dovepress}

including emerging trends and innovative models linking education, research, and health care services. The manuscript management system is completely online and includes a very quick and fair peer-review system. Visit http://www.dovepress.com/testimonials.php to read real quotes from published authors. 